\title{
Teaching Practice and Exploration of Engineering Mathematics Based on Informatization
}

\author{
Yue Yang ${ }^{1, *}$, Jun Xie $^{1}$ and Meili Zhang ${ }^{1}$ \\ ${ }^{1}$ Department of Mathematics, Dalian Naval Academy, Dalian 116018, China \\ *Corresponding author. Email: yangyue22088@163.com
}

\begin{abstract}
How to make mathematics a fun course closely related to life is urgent problems for college teachers. Informationalized teaching provides a new turn for Engineering Mathematics, which can significantly improve the teaching efficiency, make some difficult mathematical theorem definitions vivid, create an interesting classroom and increase the participation of students. This paper carries out the reform and exploration of Engineering Mathematics course from teaching strategy, informationalized instructional design, resource development, mathematics experiment and innovation evaluation, which can be effectively applied to the teaching practice and improve the teaching effect.
\end{abstract}

Keywords: informationalized teaching; engineering mathematics; teaching reform; teaching strategy;

informationalized instructional design

\section{INTRODUCTION}

Informationalized teaching is a new teaching system supported by modern informationalized technology[1]. Informatization is not only an important content of educational modernization, but also a key way to promote educational modernization. Informationalized teaching mode is based on the way of information transmission in modern teaching environment and students' psychological process of knowledge and information processing. Informationalized teaching is to make full use of the modern educational technology, create a good learning environment, and give full play to students' initiative, enthusiasm and creativity under the organization and guidance of teachers. In order that students can really become active constructors of knowledge and information[2]. For the course of Engineering Mathematics, informationalized technology can develop rich learning resources for students, provide them with a learning environment of observation, thinking and communication, and enable students to carry out creative learning activities. Therefore, informationalized teaching is an opportunity for the course of Engineering Mathematics to change the traditional teaching method.

\section{EXISTING PROBLEMS}

Engineering Mathematics is an important basic course in the undergraduate stage. It is closely related to many disciplines and plays an irreplaceable role in cultivating thinking. Due to the rich knowledge, abstract concepts, diverse thinking and wide application, students have difficulties in learning. And the teaching effect is not ideal.
Currently teaching still has the following problems: (1) the level of students is uneven and individual differences are ignored. With the expansion of enrollment scale, the differences of students are becoming more and more obvious. The "one size fits all" approach in traditional teaching often leads to the consequences of polarization. (2) The current teaching focuses on the interpretation of concepts, the derivation of formulas, the proof of theorems and the calculation of examples, but less on the application of knowledge, which makes students feel that mathematics is far from practice, resulting in the illusion of "learning is useless" and lack of ability to solve practical problems. (3) Limited by the compression of teaching materials and class hour, the teaching method is single. Students passively accept book knowledge and lack active learning and cooperative communication, resulting in low learning enthusiasm. The improper use of multimedia courseware will even aggravate students' fatigue and reduce learning effect.

\section{CHARACTERISTICS OF INFORMATIONALIZED TEACHING}

\subsection{Characteristics}

- Multimedia teaching materials. Using multimedia technology, the teaching content can be expressed structurally, dynamically and vividly. In addition to books, the teaching contents can cooperate with audio, video, animation and other teaching resources[3].

- Resource networking. The network connects the educational and teaching resources all over the 
world and all users can share these educational and teaching resources.

- Individualized teaching. Using the interactive characteristics of computers, instruction can be implemented according to the different characteristics and needs of students, so as to promote personalized education.

- Learning autonomy. The teaching supported by 9formationalized technology emphasizes studentscentered, carrying out asynchronous teaching in the network environment, so that students have more opportunities for autonomous learning.

- Cooperative activities. Through network and other informationalized technology, students can communicate face-to-face or long-distance, or in real-time or non-real-time, so that they can complete their learning tasks through cooperation.

- Management automation. With the help of computer and corresponding management software, we can realize paperless examination, problem diagnosis, task allocation and teaching management, which promote the automation of teaching management and improve the efficiency and effect.

- Environment virtualization. Information technology can create a brand new teaching environment without the limitation of space and time, such as establishing virtual classroom, laboratory, community, library and so on.

\subsection{Differences between Traditional Teaching and Informationalized Teaching}

The differences between traditional teaching and informationalized teaching are shown in Table 1 .

Table 1. Comparison Between Traditional Teaching and Informationalized Teaching

\begin{tabular}{|l|l|l|}
\hline Category & \multicolumn{1}{|c|}{ Traditional teaching } & \multicolumn{1}{c|}{ Informationalized teaching } \\
\hline Concept & Students passively accept knowledge & $\begin{array}{l}\text { Students actively accept knowledge and develop } \\
\text { themselves }\end{array}$ \\
\hline Focus & The mastery of subject knowledge & $\begin{array}{l}\text { Students' autonomy and the development of their } \\
\text { intelligence }\end{array}$ \\
\hline Objectives & Discipline specialization & Diversification of disciplines \\
\hline Content & Putting forward questions has known answers & Solve problems with multiple possible answers \\
\hline Method & Teachers' subjective injection & Design teaching and learning method \\
\hline Devices & Boring, rigid and single & Specific, vivid and lively \\
\hline Teachers & Subject specialists & Promoters and guides \\
\hline Students & A single form of class activities & Participate in the whole process of classroom teaching \\
\hline
\end{tabular}

\section{MEASURES FOR \\ INFORMATIONALIZED TEACHING OF ENGINEERING MATHEMATICS}

\subsection{Creating an Informationalized Teaching Environment}

Informationalized teaching environment is a place serving teaching and learning under the guidance of modern educational theory and relying on modern informationalized technology. The place can be a physical learning space, such as multimedia network teaching classroom, digital library, smart classroom, etc.; It can also be a virtual cyberspace, such as online courses, virtual classes, mobile apps, etc. It not only provides teachers with high-quality teaching resources and flexible teaching modes, but also provides students with diversified learning ways and learning methods[4].
On the other hand, it's important to improve teachers' ability of informationalized teaching. Training and discussion can help teachers to serve teaching with informationalized technology, promote skills of applying technology, and gain experience of instructional design and research. Provided with sufficient autonomy in action, teachers have the opportunity to give full play to their subjective initiative and carry out the practice of informationalized teaching reform.

\subsection{Developing Informationalized Teaching Resources}

The development and use of informationalized teaching resources should be sufficient and appropriate not just for the sake of use. Teachers should pay attention to the purpose, direction, scientificity, flexibility and predictability. They should select more reliable and authoritative resources according to the teaching objectives in the teaching and learning activities , and properly 
process the resources to meet the requirements of the curriculum and classroom teaching.

\subsection{Making Good Use of Informationalized Teaching Strategies}

Teaching strategies include creating situations - stimulating motivation, clarifying intention-presenting content, providing guidancee-promoting processing, designing interactive-guiding participation, reviewing and summarizing-promoting reflection, etc. Teaching strategies have certain goal-orientation and are also limited by systematic teaching design.

Significantly, there is no universal and fixed teaching strategy. Teaching strategy is a specific teaching organization form under the guidance of certain teaching and learning theory. It points to specific problem situations, specific teaching contents and objectives. Only in specific conditions, teaching strategy can play its value.

\subsection{Founding Informationalized Teaching Mode}

Under the guidance of advanced teaching concept, the informationalized teaching mode takes the cultivation of students' ability as the goal, the appropriate information environment as the support, the sufficient teaching resources as the foundation, the reasonable teaching structure as the framework, and the diversified teaching evaluation as the standard.

Through multimedia courseware, combined with Mu class, flipped classroom design and MATLAB and other mathematical software, teachers can bring lots of application problems into the exercises or assignments and establish a new teaching concept. That can improve the students' abilities in scientific computing, innovation and combination theory with practice[5].

Of the times, online and offline blended teaching can make up for the limitations of traditional teaching mode in space and time. With the help of network and smart phone, students can use fragmented time to learn anytime and anywhere depending on their circumstances. Finally, "knowledge transferred outside the classroom and internalized in the classroom" could be realizes. In traditional teaching, because of the individual differences in students' ability to understand and comprehend knowledge, the effect of classroom teaching is difficult to be consistent. Due to the lack of teaching resources, it is difficult for students to get related guidance and advice after class in time, which is easy to frustrate students' enthusiasm for active learning.

In the actual teaching, we need to choose the teaching mode according to the teaching objectives, learning contents, learners' characteristics, teachers' own characteristics, teaching conditions, curriculum characteristics and so on. With the development of information technology and the renewal of educational ideas, students' needs for teaching are becoming more specific and individual. To keep pace with the times, the informationalized teaching mode also needs continuous development and innovation. Teachers have to constantly study, practice, summarize and form a unique and effective informationalized teaching mode, which will improve teaching efficiency, effect and level.

\subsection{Innovating Informationalized Teaching Evaluation}

The knowledge points of Engineering Mathematics are coherent and closely related, and it is difficult to gain. In order to improve the learning effect and cultivate the students' learning consciousness and urgency, the mid-term and final tests can be divided into chapter tests or learning process tests. Such dynamic assessment can stimulate the students' desire for knowledge and exploration, and students' chapter or course learning can also be assessed in the form of report. The diversification of evaluation means is an effective way to improve the quality of classroom learning[6].

Informationalized teaching evaluation regards students as the center and serves the whole teaching process, making students change from passive evaluators to evaluation subjects and active participants. It helps to promote students' autonomous learning and self-development, and provide them with lifelong learning ability. During evaluating, teachers should formulate the standards in advance, based on the real performance of students as far as possible. Students' self-evaluation and mutual evaluation should be encouraged. To achieve real diversification, observation points and indicators from multiple angles and levels could be set up.

The implementation of Engineering Mathematics blended teaching mode, offline classroom teaching and online autonomous learning will inevitably force the reconstruction of the curriculum evaluation system and present diversified characteristics, including the diversification of evaluation subjects (teachers, students, network platforms, etc.), the diversification of evaluation basis (classroom performance, written homework, online learning length, online task, etc.) and the diversification of evaluation methods (combination of summative evaluation and process evaluation, combination of traditional teaching evaluation and information-based teaching evaluation, etc.)

\subsection{Paying Attention to Teachers and Students}

The new concept of teacher-student development emphasizes that teachers change from imparters to guides and helpers; Students change from passive learner to active participant. Through computer, micro class and other media resources, teaching become personalized and effective. The teaching resources focus on students development and cultivating their innovation and creativity. Therefore, teachers in the informational environment 
should not only obtain new technologies, but also make breakthroughs in informationalized teaching strategies or methods. Teachers should change their authority, function, relationship and mission to improve their knowledge structure and their personality quality constantly.

While emphasizing the basic theories and skills, teachers should give students more opportunities to participate in the teaching process, promote students' active thinking and cultivate their critical spirit.

Mathematical modeling is a good method. The process of mathematical modeling can not only test students' mastery of theoretical knowledge, but also cultivate students' ability to solve practical problems.

With the development of computer and the popularization of mathematical software package, mathematical experiment provides a better way to visualize the course of Engineering Mathematics. Students no longer only obtain abstract mathematical knowledge from books. By using mathematical software such as MATLAB, students can understand mathematical concepts intuitively and gain interest in mathematics.

\section{INFORMATIZED INSTRUCTIONAL DESIGN OF ENGINEERING MATHEMATICS}

The general model of instructional design is mainly composed of the following aspects, as shown in Fig. 1

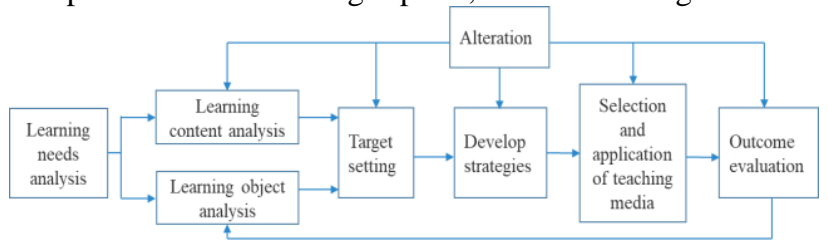

Figure 1. The general mode of instructional design

There are some main principles of informationalized instructional design.

- Set up students-centered learning environment and pay attention to the cultivation of learners' learning ability;

- Make full use of various information resources to support learning;

- Take task-driven and problem-solving as the main methods of learning and research activities, so that students can learn in meaningful situations;

- Highlight collaborative learning;

- Emphasize the evaluation of the learning process and learning resources.

The purpose of informationalized instructional design is to stimulate learning. By using the informational link, students are expected to explore, practice, think. And they can have advanced thinking activities, such as comprehensive application, problem solving, information literacy, innovative spirit, so as to complete the teaching task.

Informationalized instructional design is the developmental stage of traditional design, which is due to the change of information technology, teaching environment and teaching activities. Therefore, informationalized instructional design has the characteristics of traditional instructional design as well as the new characteristics. In the informationalized environment, the relevant theories of teaching design are still valid. But there are some specials, which need the informationalized thinking.

Principles of informationalized instructional design are listed.

- Take students as the center and pay attention to the cultivation of learners' ability;

- Make full use of all kinds of informational resources to support learning;

- Take "task-driven" and "problem solving" as the main points of learning and research activities, which makes learning meaningful;

- Emphasize collaborative learning;

- Underline the evaluation of learning process and learning resources.

In short, information-based instructional design puts forward new requirements for teachers. It requires teachers to have the ability of instructional design, especially the ability to use information technology to highlight the key points and breakthrough the difficult points. Teachers should make full use of information technology and resources in teaching to cultivate students' information literacy, innovative spirit, practical and comprehensive ability, so as to enhance their learning ability.

\section{CONCLUSION}

The teaching reform of Engineering Mathematics is a longterm project. Teachers should make full use of informationalized teaching means and carry out mixed teaching in various forms to improve the pertinence and effectiveness of teaching. In the process of curriculum construction and reform, teachers should also constantly improve their information ability and change their teaching mode to be the students' promoters to acquire knowledge and skills. Finally, the deep integration of education and teaching theory based on information technology will be achieved. Teachers and students grow together and teacher will cultivate more high-quality talents with comprehensive ability.

\section{ACKNOWLEDGMENT}

Thanks for the support of the Department of foundation's 2021 preliminary research fund. Thanks for the help of my colleagues and the cooperation of our students. 


\section{REFERENCES}

[1] Kuanna Huang. "Practical Research on the Integration of Information Technology and Advanced Mathematics Curriculum," Chongqing: Master's Thesis of Southwest University,2009. (In Chinese)

[2] Yongbo Yuan, "Comparison between informationalized teaching mode and traditional teaching mode," in China audio visual education, 2001, vol 08, pp. 26-28. (In Chinese)

[3] Xinfan Wang. "Research on The Teaching Mode of College Mathematics based on Modern Educational
Technology," in Journal of Zhuzhou Institute of Technology, 2005, vol 19(1), pp. 115-118. (In Chinese)

[4]Yichun Zhang, "Putting Information Technology into Student-based Classroom," in Jiangsu Education, 2017, vol 8. (In Chinese)

[5] Yumei Wang, "Matlab program design and mathematical experiment," in Electronic technology, 2013, vol 9, pp.65-66. (In Chinese)

[6] Huijie Zhou. "Exploration of College Mathematics Teaching based on information technology," in Chinese Education Informatization, 2013. (In Chinese) 